CASE REPORT

\title{
Rosiglitazone for prevention or adjuvant treatment of Nelson's syndrome after bilateral adrenalectomy
}

Mikkel Andreassen and Lars Østergaard Kristensen

Department of Endocrinology and Internal Medicine, J 106, Herlev Hospital, University of Copenhagen, Herlev Ringvej, 2730 Herlev, Denmark

(Correspondence should be addressed to M Andreassen; Email: andreassenmikkel@hotmail.com)

\begin{abstract}
Objective: To investigate the effect of Rosiglitazone in three patients treated with bilateral adrenalectomy followed by hyperpigmentation and hypersecretion of ACTH.

Patients and methods: One patient had increasing ACTH after previous transsphenoidal surgery for Nelson's syndrome, and two patients without pituitary adenomas had recurrence of Cushing's disease after primary and repeated transsphenoidal surgery with need for bilateral adrenalectomy. The patients developed hyperpigmentation and increasing ACTH at nadir $2-4 \mathrm{~h}$ after morning hydrocortisone dose. ACTH during Rosiglitazone therapy ( $4 \mathrm{mg}$ /day for 4 weeks and then $8 \mathrm{mg} /$ day) was measured at regular intervals $24 \mathrm{~h}$ after the latest dose of hydrocortisone.

Results: In two patients there was a decrease in ACTH by $40 \%$ after 5 months. The first of these patients showed an escape with increasing ACTH to the initial value after 11 months. In the third patient no effect was observed. Tumour development or progression on magnetic resonance imaging was not observed.

Conclusion: Rosiglitazone might represent an adjuvant therapy in patients with ACTH hypersecretion. Larger long-term studies are needed.
\end{abstract}

European Journal of Endocrinology 153 503-505

\section{Introduction}

Bilateral adrenalectomy is an option of treatment after unsuccessful transsphenoidal surgery (TSS) and recurrence of Cushing's disease. A considerable fraction of these patients need bilateral adrenalectomy (1). A complication of bilateral adrenalectomy is Nelson's syndrome with adrenocorticotrophin (ACTH) hypersecretion, hyperpigmentation and possibly development of pituitary tumour. Radiotherapy is partially prophylactic, but implicates the risk of pituitary insufficiency and also damage of the optic chiasma. Therefore, the recent suggestion for treatment is TSS in cases with tumour, but tumour is not always present. An acute effect of bromocriptine in Nelson's syndrome has been observed (2) and long-term remission with cabergoline has been reported in a single patient (3).

Peroxisome proliferator-activating receptor- $\gamma$ (PPAR$\gamma$ ) is a member of the nuclear hormone receptor superfamily $(4,5)$. PPAR- $\gamma$ receptors are predominantly expressed in adipose tissue $(6,7)$. Importantly in this context it has recently been shown that PPAR- $\gamma$ is also expressed in normal ACTH-secreting cells and abundantly in ACTH-secreting tumour cells (8).

Rosiglitazone is a PPAR- $\gamma$ ligand. It is a member of the thiazolidinedione class of insulin-sensitizing drugs.
In vitro treatment of human ACTH-secreting pituitary tumour cells with Rosiglitazone leads to enhanced apoptosis and decreased cell division and in vivo studies reveal that Rosiglitazone is able to inhibit ACTH secretion and tumour growth in mice (8). Furthermore, Rosiglitazone has been used as short-term therapy in Cushing's disease in humans (9). Based on these observations we have employed Rosiglitazone in three patients with Nelson's syndrome.

\section{Patients and methods}

\section{Patients}

Patient 1 was a 67 -year-old female with Cushing's disease diagnosed in 1970. Primary treatment was bilateral adrenalectomy. Gradually increasing ACTH and hyperpigmentation was observed from about 1990. In 1998 magnetic resonance imaging (MRI) showed a pituitary adenoma with suprasellar extension close to the optic chiasma. TSS was performed with temporary improvement, but in 2002 there was recurrence of Nelson's syndrome with increasing ACTH and relapse of a small $(7 \times 7 \times 3 \mathrm{~mm})$ pituitary adenoma.

Patient 2 was a 74 -year-old male with Cushing's disease diagnosed in 1993. Initially successful treatment 
with TSS was performed, but in 1999 recurrence was diagnosed. Another TSS was attempted without success, and in 2000 bilateral adrenalectomy was performed. 2 years later hyperpigmentation and increasing ACTH occurred. There was no visible tumour on MRI.

Patient 3 was a 37-year-old female with Cushing's disease diagnosed in 2002. TSS was performed as a primary treatment without cure and a second TSS was also ineffective, whereafter laparascopically bilateral adrenalectomy was done. Due to residual disease activity a second open operation was performed on the left adrenal gland. Clinically the patient was cured and hydrocortisone-replacement therapy was initiated but, apparently, low endogenous cortisol production was still present. Since 2003 the patient has shown hyperpigmentation and increasing ACTH, but there is no visible tumour on MRI.

All patients received hydrocortisone-replacement therapy of $20-30 \mathrm{mg} /$ day divided into two or three doses.

\section{Methods}

During Rosiglitazone therapy ( $4 \mathrm{mg}$ /day for 4 weeks and then $8 \mathrm{mg} /$ day) ACTH was measured at regular intervals $24 \mathrm{~h}$ after the latest dose of hydrocortisone at nadir cortisol, when zenith ACTH could be expected.

Plasma ACTH was measured with a high-detectability immunoradiometric assay (DYNOtest; BRAHMS Diagnostica GmbH, Berlin, Germany). The normal range is $1.8-12 \mathrm{pM}$. Serum cortisol was measured with RIA (Diagnostic System Laboratories, Webster, TX, USA); the lower limit of detection was $10 \mathrm{nM}$.

No side effects were reported, including any episodes of hypoglycaemia. Liver-function tests were performed at every visit and remained normal during the study. This retrospective report was approved by the Danish Data Protection Agency, Copenhagen.

\section{Results}

Figure 1 shows ACTH during Rosiglitazone treatment. Patients 1 and 2 showed a gradual decrease in ACTH by $40 \%$ after $3-6$ months (patient 1 from 1290 to $765 \mathrm{pM}$ and patient 2 from 478 to $289 \mathrm{pM}$ ). However, in patient 1 there was an escape after 5 months of treatment, with ACTH increasing to the initial value, and the treatment has now been paused. Patient 3 received Rosiglitazone for 1 year, during which time no effect on ACTH was observed, and the treatment has recently been stopped and so far no increase in ACTH has been observed. Hyperpigmentation did not improve in any of the patients.

MRI of the pituitary showed no evidence of tumour progression in patient 1 and no development of tumours in patients 2 and 3.

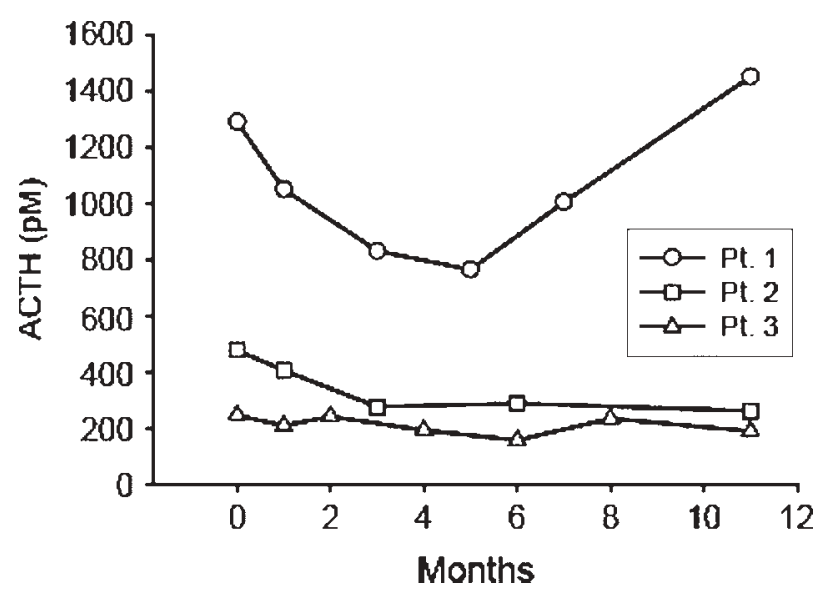

Figure 1 Plasma ACTH (pM) during Rosiglitazone treatment. Measurements of ACTH were taken $24 \mathrm{~h}$ after the latest hydrocortisone dose.

\section{Discussion}

Hypersecretion of ACTH with hyperpigmentation is the key characteristic of Nelson's syndrome and an obvious pituitary tumour is not always present (10). According to this criterion there is no doubt that our three patients had Nelson's syndrome.

In two of the patients Rosiglitazone treatment lead to a significant decrease in ACTH, assumed to reflect secretion, but in one of these patients there was an escape of the effect. The third patient did not respond. This patient had low residual endogenous cortisol production, which might be of some importance in reducing corticotrophic ACTH secretion and cell proliferation. Concerning cell proliferation it should be noted that the residual tumour in one patient did not progress and that tumour development was not observed in the other two patients.

In order to separate potential responders from nonresponders it would have been of interest to evaluate PPAR$\gamma$ receptor expression in tumours already removed, but such an analysis was not performed. However, Ambrosi et al. (9) observed no correlation between PPAR- $\gamma$ expression and response to Rosiglitazone in patients with Cushing's disease.

Rosiglitazone did not lead to normalization of ACTH in any of our patients. However, it seems worthwhile to consider an attempt of such treatment in patients with Nelson's syndrome without obvious tumours and possibly in patients after unsuccessful TSS for a pituitary adenoma hypersecreting ACTH. Furthermore, the medical treatment might be used in concert with radiotherapy during the time period awaiting the effect of radiation.

PPAR- $\gamma$ is also expressed in a variety of other pituitary tumours (6). This current information and the present results point to the possibility that thiazolidinedione represents an option of treatment for Nelson's 
syndrome and, potentially, other pituitary tumors. Larger long-term studies are needed to elucidate the answers to these questions. A new generation of thiazolidinediones developed selectively for this specific purpose would be of considerable interest. This may bring about a change in the strategy towards medical treatment of a variety of pituitary tumors, analogous to the well-established first-line medical treatment of prolactinomas with dopamine agonists.

\section{Acknowledgements}

We thank chief laboratory technician Ulla KjerulffHansen and her team for skilled technical assistance.

\section{References}

1 Rees DA, Hanna FWF, Davies JS, Mils RG, Vafidis J \& Scanion MF. Long-term follow-up results of Cushing's disease in a single centre using strict criteria for remission. Clinical Endocrinology 200256 $541-551$.

2 Leilani B, Mercado-Asis LB, Yanovski JA, Tracer HL, Chik CL \& Cutler CB. Acute effects of bromocriptine, cyproheptadine, and valproic acid on plasma adrenocorticotropin secretion in Nelson's syndrome. Journal of Clinical Endocrinology and Metabolism 1997 82 514-517.
3 Pivonello R, Faggiano A, Di Salle F, Filippella M, Lombardi G \& Colao A. Complete remission of Nelson's syndrome after 1-year treatment with cabergoline. Journal of Endocrinological Investigation $199911860-865$.

4 Spiegelman BM. PPAR- $\gamma$ : adipogenic regulator and thiazolidinedione receptor. Diabetes $1998 \mathbf{4 7} 507-514$.

5 Mangelsdorf DJ, Thummel C, Beato M, Herrlich P, Schutz G, Umesono K, Blumberg B, Kastner P, Mark M, Chambon P \& Evans RM. The nuclear receptor superfamily: the second decade. Cell 199583 835-839.

6 Heaney AP. Novel pituitary ligands: peroxisome proliferator activating receptor- $\gamma$. Pituitary $20036153-159$.

7 Heaney AP, Fernando M \& Melmed S. PPAR- $\gamma$ receptor ligands: novel therapy for pituitary adenomas. Journal of Clinical Investigation $20031111381-1388$.

8 Heaney AP, Fernando M, Yong WH \& Melmed S. Functional PPAR-yreceptor is a novel therapeutic target for ACTH-secreting pituitary adenomas. Nature Medicine 20028 1281-1287.

9 Ambrosi B, Dall'Asta C, Cannavo S, Libé R, Vigo T, Epaminonda P, Chiodini I, Ferrero S, Trimarchi F, Arosio M \& Beck-Peccoz P. Effects of chronic administration of PPAR- $\gamma$ ligand rosiglitazone in Cushing's disease. European Journal of Endocrinology 2004 151 173-178.

10 Kelly PA, Samandouras G, Grossman AB, Afshar F, Besser GM \& Jenkins PJ. Neurosurgical treatment of Nelson's syndrome. Journal of Clinical Endocrinology and Metabolism 200287 5465-5469.

Received 24 March 2005

Accepted 6 July 2005 